\begin{tabular}{|l|l}
\hline FRI0301 & DO PATIENTS AND PHYSICIANS AGREE ON THE \\
DEFINITION OF REMISSION AND LOW DISEASE \\
ACTIVITY IN AXIAL SPONDYLOARTHRITIS?
\end{tabular}

M. Valero ${ }^{1}$, J. Bachiller-Corral' ${ }^{1}$, B. A. Blanco Cáceres ${ }^{1}$, M. Á. Blázquez ${ }^{1}$, C. Díaz-Miguel', M. J. Garcia Villanueva' ${ }^{1}$, C. Larena ${ }^{1}$, J. L. Morell Hita', C. De la Puente Bujidos ${ }^{1}$, A. Rodriguez-García ${ }^{1}$, M. Vázquez Díaz ${ }^{1}$, A. Moltó ${ }^{2}{ }^{1}{ }^{1}$ Hospital Universitario Ramón y Cajal, Rheumatology, Madrid, Spain; ${ }^{2}$ Hôpital Cochin APHP Hôpital Cochin - APHP Centre and INSERM U-1153, Université de Paris., Rheumatology department, Paris, France

Background: Current recommendations for axial Spondyloarthritis (axSpA) include the treat-to-target concept and suggest that the ideal target should be remission or low disease activity (LDA). Also, the importance of a shared decision is highlighted. Unfortunately, the definition of remission is not consensual, and most of the definitions are difficult to evaluate in clinical practice

Objectives: To propose an evaluation of remission by a single question to the patient, by comparing it to the different available definitions. To analyze the metric properties of the current definitions against patient's perception

Methods: One-center cross-sectional study in a tertiary care hospital including consecutive patients with a diagnosis of axSpA (and fulfilling the ASAS criteria) were included between February to November 2019. Patient's perception of remission and LDA was evaluated by a single question. Physician's perception of remission and LDA was assessed identically. The level of agreement between patients' perception and the other available definitions was tested by the Prevalence and Bias adjusted Kappa (PABAK). The metric properties Sensitivity (S) and Specificity (Sp) of the available definitions (BASDAl cut-offs, ASDAS disease states, ASAS criteria for partial remission and patient acceptable symptom state), were tested against the patients perspective, as the gold standard.

Results: A total of 105 axSpA patients were included. $63,8 \%$ were males and $67,6 \%$ had radiographic sacroilitis (Table 1). $21 \%$ and $72 \%$ of them considered themselves in remission and LDA, respectively. Physician's perception was $45.7 \%$ and $81 \%$ for remission and LDA, respectively. The prevalence of the different definitions are shown in Figure 1. The best agreement for patients's perception of remission was found with a BASDAI $<2+$ normal CRP (Table 2). This definition was also the most sensitive $(\mathrm{S}=72,7 \%)$ and specific $(\mathrm{Sp}=83,1 \%)$ when taking the patient's perception as a reference.

Table 1. Characteristics of 105 patients with axSpA

\begin{tabular}{lcccr}
\hline & All (N:105) & $\begin{array}{c}\text { Patients in } \\
\text { self-defined } \\
\text { REM (N:22) }\end{array}$ & $\begin{array}{c}\text { Patients in } \\
\text { self-defined } \\
\text { LDA (N:54) }\end{array}$ & $\begin{array}{r}\text { Patients No } \\
\text { REM no LDA } \\
\text { (N:29) }\end{array}$ \\
\hline Male, n (\%) & $67(63,8)$ & $18(81,8)$ & $34(63)$ & $15(51,7)$ \\
r-axSpA, n (\%) & $71(67,6)$ & $17(77,3)$ & $33(61,1)$ & $21(72,4)$ \\
Mean age, years (SD) & $49(13)$ & $51(15)$ & $47(13)$ & $50(11)$ \\
Mean AxSpA duration, & $12,2(13)$ & $17,1(16,2)$ & $11,2(11,7)$ & $10,3(12,3)$ \\
$\quad$ years (SD) & & & & \\
HLA- B27+, n (\%) & $72(69,2)$ & $17 / 22(77,3)$ & $33 / 54(61,1)$ & $22 / 28(78,6)$ \\
Data from 104 & & & & \\
Periferic arthritis, n (\%) & $34(32,4)$ & $7(31,8)$ & $17(31,5)$ & $10(45,4)$ \\
Uveitis, n (\%) & $22(21)$ & $6(27,3)$ & $10(18,5)$ & $6(20,7)$ \\
Biological treatment, n (\%) & $43(41)$ & $14(63,6)$ & $19(35,1)$ & $10(34,5)$ \\
CRP, mean (SD) & $3,61(5,36)$ & $2,31(2,17)$ & $2,84(3,87)$ & $6,04(8,14)$ \\
ASDAS, mean (SD) & $1,78(1,08)$ & $0,98(0,71)$ & $1,63(0,89)$ & $2,68(1,03)$ \\
BASDAI, mean (SD) & $3,35(2,32)$ & $1,39(1,30)$ & $3,13(1,84)$ & $5,26(2,33)$ \\
BASFI, mean (SD) & $2,81(2,45)$ & $1,24(1,37)$ & $2,57(2,00)$ & $4,43(2,92)$ \\
\hline
\end{tabular}

Table 1.REM: Remission; LDA: Low Disease Activity; SD: Standard Desviation; CRP: C-Reactive Protein IBD: Inflammatory Bowel Disease.

Figure 1. Remission/ Low disease activity prevalence

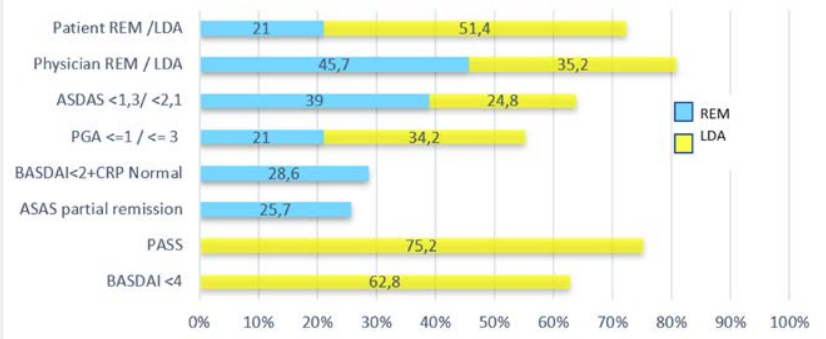

Fig. 1. REM/LDA: remission/ low disease activity self-defined patient or physician through a simple question. ASDAS <1,3: inactive disease; ASDAS <2,1: low activity; PGA: Patient global assessment; PASS: Patient acceptable symptom state.
Table 2. Agreement between different definitions of remission

\begin{tabular}{lccccc}
\hline & ASDAS $<1,3$ & $\begin{array}{c}\text { BASDAl }<2+ \\
\text { Normal CRP }\end{array}$ & PGA $\leq 1$ & $\begin{array}{c}\text { Physician } \\
\text { REM }\end{array}$ & $\begin{array}{c}\text { Patient } \\
\text { REM }\end{array}$ \\
\hline ASAS PR & $0.53(0.58)$ & $0.59(0.68)$ & $0.76(0.83)$ & $0.22(0.26)$ & $0.39(0.56)$ \\
ASDAS $<1,3$ & & $0.64(0.68)$ & $0.50(0.56)$ & $0.44(0.45)$ & $0.28(0.37)$ \\
BASDAl $<2+$ & & & $0.60(0.69)$ & $0.25(0.28)$ & $0.50(0.62)$ \\
Normal CRP & & & & $0.20(0.24)$ & $0.42(0.62)$ \\
PGA $\leq 1$ & & & & $0.20(0.24)$ \\
Physician REM & & & & &
\end{tabular}

Agreement is presented as Cohen's Kappa (PABAK: prevalence and bias adjusted kappa). Patient and Physician remission (REM) are based on the single question; ASAS PR: ASAS partial remission; PGA: Patient global assessment.

Conclusion: In this real-life population, the evaluation of remission by the patient through a single question was shown to be feasible and to present an acceptable agreement with other definitions.

References:

[1] Gorlier C, et al. Ann Rheum Dis 2019;78(2):201-8.

Acknowledgments: To Ansgar Seyfferth and Alfonso Muriel. To Carlos Sanchez-Piedra, Fernando Alonso and Mercedes Guerra from Sociedad Española de Reumatología, Research Unit.

Disclosure of Interests: Marta Valero Grant/research support from: Novartis, Pfizer, Abvie, Speakers bureau: Novartis, Celgene, Javier Bachiller-Corral: None declared, Boris Anthony Blanco Cáceres: None declared, M. Ángeles Blázquez: None declared, Consuelo Díaz-Miguel: None declared, Maria Jesus Garcia Villanueva: None declared, Carmen Larena: None declared, Jose Luis Morell Hita: None declared, Carlos De la Puente Bujidos: None declared, Ana Rodriguez-García: None declared, Mónica Vázquez Díaz: None declared, Anna Moltó Grant/research support from: Pfizer, UCB, Consultant of: Abbvie, BMS, MSD, Novartis, Pfizer, UCB

DOI: 10.1136/annrheumdis-2020-eular.3301

\begin{tabular}{|l|l}
\hline FRI0302 & WHAT IS THE IMPACT OF DISCREPANCY BETWEEN \\
CENTRAL AND LOCAL READERS IN EVALUATION \\
OF MRI SCANS ON THE CLASSIFICATION OF AXIAL \\
SPONDYLOARTHRITIS? DATA FROM THE ASAS \\
CLASSIFICATION COHORT STUDY
\end{tabular}

W. P. Maksymowych ${ }^{1,2}$, S. Juhl Pedersen ${ }^{3}$, U. Weber ${ }^{4}$, P. M. Machado ${ }^{5}$, X. Baraliakos ${ }^{6}$, J. Sieper ${ }^{7}$, S. Wichuk ${ }^{1}$, D. Poddubnyy ${ }^{7}$, M. Rudwaleit ${ }^{8}$, D. Van der Heijde ${ }^{9}$, R. B. M. Landewé ${ }^{10}$, J. Paschke ${ }^{2}$, M. Ǿstergaard ${ }^{3}$, R. G. Lambert ${ }^{1}$ ${ }^{1}$ University of Alberta, Edmonton, Canada; ${ }^{2}$ CARE Arthritis, Edmonton, Canada; ${ }^{3}$ Copenhagen University, Copenhagen, Denmark; ${ }^{4}$ University of Southern Denmark, Sønderborg, Denmark; ${ }^{5}$ University College London, London, United Kingdom; ${ }^{6}$ Rheumazentrum Ruhrgebiet, Herne, Germany; ${ }^{7}$ Charité - Universitätsmedizin Berlin, Berlin, Germany; ${ }^{8}$ Klinikum Bielefeld, Bielefeld, Germany; ${ }^{9}$ Leiden University Medical Center, Leiden, Netherlands; ${ }^{10}$ University of Amsterdam, Amsterdam, Netherlands

Background: Active MRI lesions typical of axial spondyloarthritis (axSpA) were reported in $61.6 \%$ and $2.2 \%$ of axSpA and not-axSpA patients, respectively, from the ASAS classification cohort (ASAS-CC) ${ }^{1}$. Discrepancy between local and central reader evaluation of MRI scans could result in differences in numbers of patients fulfilling the imaging arm of the ASAS classification criteria. But final classification may not be impacted if discrepant patients still fulfill the clinical arm. Objectives: We aimed to assess the impact of reader discrepancy in detection of active MRI lesions on the number of patients classified as having axSpA in patients recruited to the ASAS-CC.

Methods: MRI images of the sacroiliac joints (SIJs) were available from 252 cases in the ASAS-CC, and these also had clinical and radiographic data. Seven central readers from the ASAS-MRI group recorded MRI lesions in an eCRF that included active lesions typical of axSpA in the SIJ (MRI-active) that was worded exactly the same as in the original ASAS-CC eCRF permitting comparisons between central and local site readers. Active lesions were deemed to be present according to majority agreement $(\geq 4 / 7)$ of central readers and also any 2 central readers. We calculated the number of patients that were classified differently after central evaluation for overall fulfilment of the ASAS criteria and for the imaging arm.

Results: Discordance between central and local readers for detection of MRI-active was recorded in $45(17.8 \%)$ and $47(18.2 \%)$ of cases according to 2-reader and majority $(\geq 4 / 7)$ central reader data, respectively (kappa $(95 \% \mathrm{Cl})$ of 0.64 (0.54-0.73) and $0.62(0.53-0.72)$. With central reading as external standard the false-positive rate for active lesions was $26.9 \% \%$ and $32.2 \%$ ('local overcall') for 2-reader and majority reader data, respectively. There were $159(63.1 \%)$ patients who fulfilled the ASAS axSpA criteria based on local-reading, and $148(58.7 \%)$ and $143(56.7 \%)$ patients based on 2-reader and majority central-reading, respectively (Table). When fulfillment of the imaging arm was the primary consideration 
(irrespective of the clinical arm), 126 (50\%) patients fulfilled the criteria based on local-reading, and 111 (44\%) and 102 (40.5\%) patients based on 2-reader and majority central-reading, respectively.

Conclusion: Despite substantial overcall for positive MRI SIJ inflammation by local readers, the number of patients classified as having axSpA did not change substantially. This is due to the alternate mechanism for classification through the clinical arm.

References:

[1] Rudwaleit et al. Ann Rheum Dis 2009;68: 777-83

Impact of Central Vs. Local Reader SIJ MRI Inflammation Assessment on SpA Classification in cases with all clinical, radiographic, and central and local MRI inflammation data available $(n=252)$

\begin{tabular}{lcccc}
$\begin{array}{l}\text { MRI assess- } \\
\text { ment used }\end{array}$ & $\begin{array}{c}\text { SpA Classification } \\
\text { = Yes N(\%) }\end{array}$ & $\begin{array}{c}\text { SpA Classification } \\
\text { = No N(\%) }\end{array}$ & $\begin{array}{c}\text { Imaging Arm SpA } \\
\text { Classification } \\
\text { Yes N(\%) }\end{array}$ & $\begin{array}{c}\text { Imaging Arm SpA } \\
\text { Classification }= \\
\text { No N(\%) }\end{array}$ \\
\hline $\begin{array}{l}\text { Local Reader } \\
\text { MRI positive }\end{array}$ & $159(63.1 \%)$ & $93(36.9 \%)$ & $126(50 \%)$ & $126(50 \%)$ \\
$>2$ Central \\
$\begin{array}{l}\text { Reader MRI } \\
\text { positive }\end{array}$ & $148(58.7 \%)$ & $104(41.3 \%)$ & $111(44.0 \%)$ & $141(56.0 \%)$ \\
$\begin{array}{l}\text { Majority } \\
\text { Central } \\
\text { Reader } \\
(\geq 4 / 7) \text { MRI }\end{array}$ & $143(56.7 \%)$ & $109(43.2 \%)$ & $102(40.5 \%)$ & $150(59.5 \%)$ \\
positive & & & & \\
\hline
\end{tabular}

Disclosure of Interests: Walter P. Maksymowych Grant/research support from: AbbVie, Novartis, Pfizer, and UCB, Consultant of: AbbVie, Boehringer Ingelheim, Celgene, Eli Lilly, Galapagos, Janssen, Novartis, Pfizer, and UCB, Employee of: Chief Medical Officer of CARE Arthritis Limited, Speakers bureau: AbbVie, Janssen, Novartis, Pfizer, and UCB, Susanne Juhl Pedersen Grant/research support from: Novartis, Ulrich Weber: None declared, Pedro M Machado Consultant of: PMM: Abbvie, Celgene, Janssen, Lilly, MSD, Novartis, Pfizer, Roche and UCB, Speakers bureau: PMM: Abbvie, BMS, Lilly, MSD, Novartis, Pfizer, Roche and UCB, Xenofon Baraliakos Grant/research support from: Grant/research support from: AbbVie, BMS, Celgene, Chugai, Merck, Novartis, Pfizer, UCB and Werfen, Consultant of: AbbVie, BMS, Celgene, Chugai, Merck, Novartis, Pfizer, UCB and Werfen, Speakers bureau: AbbVie, BMS, Celgene, Chugai, Merck, Novartis, Pfizer, UCB and Werfen, Joachim Sieper Consultant of: AbbVie, Boehringer Ingelheim, Eli Lilly and Company, Janssen, Merck, Novartis, Pfizer, Roche, and UCB Pharma, Speakers bureau: AbbVie, Boehringer Ingelheim, Eli Lilly and Company, Janssen, Merck, Novartis, Pfizer, Roche, and UCB Pharma, Stephanie Wichuk: None declared, Denis Poddubnyy Grant/research support from: AbbVie, MSD, Novartis, and Pfizer, Consultant of: AbbVie, Bristol-Myers Squibb, Eli Lilly, MSD, Novartis, Pfizer, Roche, UCB, Speakers bureau: AbbVie, Bristol-Myers Squibb, Eli Lilly, MSD, Novartis, Pfizer, Roche, UCB, Martin Rudwaleit Consultant of: AbbVie, BMS, Celgene, Janssen, Eli Lilly, MSD, Novartis, Pfizer, Roche, UCB Pharma, Désirée van der Heijde Consultant of: AbbVie, Amgen, Astellas, AstraZeneca, BMS, Boehringer Ingelheim, Celgene, Cyxone, Daiichi, Eisai, Eli-Lilly, Galapagos, Gilead Sciences, Inc., Glaxo-Smith-Kline, Janssen, Merck, Novartis, Pfizer, Regeneron, Roche, Sanofi, Takeda, UCB Pharma; Director of Imaging Rheumatology BV, Robert B.M. Landewé Consultant of: AbbVie; AstraZeneca; Bristol-Myers Squibb; Eli Lilly \& Co.; Galapagos NV; Novartis; Pfizer; UCB Pharma, Joel Paschke: None declared, Mikkel Ǿstergaard Grant/ research support from: AbbVie, Bristol-Myers Squibb, Celgene, Merck, and Novartis, Consultant of: AbbVie, Bristol-Myers Squibb, Boehringer Ingelheim, Celgene, Eli Lilly, Hospira, Janssen, Merck, Novartis, Novo Nordisk, Orion, Pfizer, Regeneron, Roche, Sandoz, Sanofi, and UCB, Speakers bureau: AbbVie, Bristol-Myers Squibb, Boehringer Ingelheim, Celgene, Eli Lilly, Hospira, Janssen, Merck, Novartis, Novo Nordisk, Orion, Pfizer, Regeneron, Roche, Sandoz, Sanofi, and UCB, Robert G Lambert: None declared

DOI: 10.1136/annrheumdis-2020-eular.6350

\section{FRI0303 1 PERIPHERAL SYMPTOMS ARE ASSOCIATED WITH LESS SPINAL RADIOGRAPHIC PROGRESSION IN PATIENTS WITH EARLY AXIAL SPONDYLOARTHRITIS: RESULTS FROM THE GERMAN SPONDYLOARTHRITIS INCEPTION COHORT}

M. Torgutalp ${ }^{1,2}$, M. Protopopov ${ }^{1}$, F. Proft ${ }^{1}$, J. Sieper ${ }^{1}$, V. Rios Rodriguez ${ }^{1}$, H. Haibel ${ }^{1}, \mathrm{M}$. Rudwaleit ${ }^{1,3}, \mathrm{D}$. Poddubnyy ${ }^{1,4}$. ${ }^{1}$ Charité Universitätsmedizin Berlin, Department of Gastroenterology, Infectiology and Rheumatology CBF, Berlin, Germany; ${ }^{2}$ Ankara University Faculty of Medicine, Division of Rheumatology, Department of Internal Medicine, Ankara, Turkey; ${ }^{3}$ Klinikum Bielefeld Rosenhöhe, Bielefeld, Germany; ${ }^{4}$ German Rheumatism Research Centre, Berlin, Germany
Background: Peripheral symptoms (PS), such as arthritis, enthesitis, and dactylitis, are common in axial spondyloarthritis (axSpA); data showing the association of PS and spinal radiographic progression in axSpA are controversial.

Objectives: To analyze the association of PS and spinal radiographic progression in patients with axSpA.

Methods: A total of 210 patients with axSpA (115 with radiographic and 95 with non-radiographic axSpA) were selected for analysis. Spinal radiographs were scored by two readers in a random order according to the modified Stoke Anky losing Spondylitis Spinal Score (mSASSS). Pelvic radiographs were scored according to the grading system of the modified New York criteria; a sacroiliitis sum score was calculated as a sum of the grades for both sacroiliac joints. Mann-Whitney and Fisher exact tests were performed for group comparisons. A multivariable regression analysis was performed to analyze the influence of PS on radiographic progression.

Results: Of the 101 (48.1\%) patients with PS, 78 had peripheral arthritis, 48 enthesitis, 12 - dactylitis. 32 patients had $\leq 1$ PS. Patients with PS were older, less frequently HLA-B27 positive, compared with patients with no PS (73 $(73.0 \%)$ vs. 93 $(85.3 \%), p=0.028)$, had higher disease activity (time-averaged ASDAS over 2 years $2.6 \pm 0.9$ vs. $2.3 \pm 0.9 ; p=0.032$ ), worse physical function (BASFI $3.5 \pm 2.3$ vs. 2.3 $\pm 2.2, p<0.001$ ), higher exposure to disease modifying anti-rheumatic drugs (39 $(38.6 \%)$ vs. $22(20.2 \%), p=0.003)$ and lower baseline radiographic sacroiliitis sum score $(3.8 \pm 1.9$ vs. $4.4 \pm 2.1, p=0.026)$; other baseline characteristics were similar. Patients with PS had lower absolute progression in mSASSS after 2 years of follow-up than those without $(0.28 \pm 1.39$ vs $1.15 \pm 2.9, p=0.045) ; 7.9 \%$ of patients with PS had a progression of mSASSS by $\geq 2$ points compared to $20.2 \%$ in patients without PS ( $p=0.011)$. Radiographic progression of sacroiliitis was similar in both groups. In a multivariable regression analysis, presence of PS was associated with a lower mSASSS progression and lower odds for the mSASSS progression by $\geq 2$ points after 2 years of follow-up: $\beta=-0.98(95 \%-1.68$ to -0.28$)$ OR=0.33 (95\% Cl 0.12 to 0.91 ), respectively - Table 1 .

Table 1. Association of peripheral symptoms with radiographic progression in axial spondyloarthritis after 2 years of follow-up.

Multivariable linear regression analysis

\section{Outcome}

mSASSS change score

Change of the sacroiliitis sum score

Multivariable logistic regression analysis

Outcome

Progression of mSASSS by $\geq 2$ points

Progression of sacroilitis by at least 1 grade in opinion of both readers

mSASSS - modified Stoke Ankylosing Spondylitis Spine Score.

*Adjusted for the smoking status, HLA-B27 status, NSAIDs intake, baseline syndesmophytes, and time-averaged ASDAS

${ }^{\star *}$ Adjusted for the smoking status, HLA-B27 status, NSAIDs intake, sacroilitis sum score at baseline, and time-averaged ASDAS.

Conclusion: Presence of PS is associated with distinct characteristics of SpA including slower radiographic spinal progression which might be explained partly by the numerically lower mSASSS score at baseline.

Acknowledgments: GESPIC has been financially supported by the German Federal Ministry of Education and Research (BMBF). As funding by BMBF was reduced in 2005 and stopped in 2007, financial support has been obtained from Abbott / Abbvie, Amgen, Centocor, Schering-Plough, and Wyeth. Since 2010 GESPIC is supported by Abbvie.

Dr. Murat Torgutalp was supported by the Scientific and Technological Research Council of Turkey (TUBITAK).

Disclosure of Interests: Murat Torgutalp: None declared, Mikhail Protopopov Consultant of: Novartis, Fabian Proft Grant/research support from: Novartis Pharma GmbH, Consultant of: Consultancy / speaker fees from: Abbvie, BMS Celgene, Lilly, MSD, Novartis, Pfizer, Roche, UCB, Speakers bureau: Consultancy / speaker fees from: Abbvie, BMS, Celgene, Lilly, MSD, Novartis, Pfizer Roche, UCB, Joachim Sieper Consultant of: AbbVie, Boehringer Ingelheim, Eli Lilly and Company, Janssen, Merck, Novartis, Pfizer, Roche, and UCB Pharma, Speakers bureau: AbbVie, Boehringer Ingelheim, Eli Lilly and Company, Janssen, Merck, Novartis, Pfizer, Roche, and UCB Pharma, Valeria Rios Rodriguez Consultant of: Abbvie, Novartis, Hildrun Haibel Consultant of: Abbvie, Jansen, MSD, and Novartis, Speakers bureau: Abbvie, Jansen, MSD, and Novartis, Martin Rudwaleit Consultant of: AbbVie, BMS, Celgene, Janssen, Eli Lilly, MSD, Novartis, Pfizer, Roche, UCB Pharma, Denis Poddubnyy Grant/research support from: AbbVie, MSD, Novartis, and Pfizer, Consultant of: AbbVie, Bristol-Myers Squibb, Eli Lilly, MSD, Novartis, Pfizer, Roche, UCB, Speakers bureau: AbbVie, Bristol-Myers Squibb, Eli Lilly, MSD, Novartis, Pfizer, Roche, UCB DOI: 10.1136/annrheumdis-2020-eular.3397 